STUDY OF COMPARISON BETWEEN EPHEDRINE AND PHENYLEPHRINE FOR PREVENTION OF HYPOTENSION DURING SPINAL ANESTHESIA FOR CESAREAN SECTION

\title{
Chandkiran Yadav.
}

Consultant Anesthesiologist, Indira IVF centre, Lucknow, UP, India.

\section{ABSTRACT}

Background: Hypotension during spinal anesthesia (SA) is common. Many agents are used for treating hypotension. In this study we compared the efficacy of ephedrine and phenylephrine in preventing and treating hypotension in spinal anesthesia for cesarean section and their effect on fetal outcome.

Methods: A total of 120 ASA Grade I patients undergoing elective cesarean section under spinal anesthesia with a normal singleton pregnancy beyond 36 weeks gestation were randomly allocated into two groups of 60 each. Group I received prophylactic bolus dose of ephedrine $10 \mathrm{mg}$ IV at the time of intrathecal block with rescue boluses of $5 \mathrm{mg}$. Group II received prophylactic bolus dose of phenylephrine $100 \mu \mathrm{g}$ IV at the time of intrathecal block with rescue boluses of $50 \mu \mathrm{g}$. Hemodynamic variables like blood pressure and heart rate was recorded every 2 minutes up to delivery of baby and then after every 5 minutes. Neonatal outcome was assessed using Apgar score at 1 and 5 minutes.

Results: There was no difference found in managing hypotension between two groups. Incidence of bradycardia was higher in phenylephrine group. The differences in Apgar score, and birth weight between two groups were found statistically insignificant.

Conclusion: From my study it was concluded that both phenylephrine and ephedrine are equally efficient vasopressor agent in management of hypotension during spinal anesthesia for elective cesarean delivery. Neonatal outcome remains equally good in both the groups.

KEY WORDS: Phenylephrine, Ephedrine, Hypotension, Spinal Anesthesia.

Address for correspondence: Dr. Chandkiran Yadav, 4/87, Vipul khand,gomati nagar, Lucknow, Uttarpradesh-226010,India. E-Mail: chandkiran11111@gmail.com

\begin{tabular}{|c|c|c|}
\hline \multirow{2}{*}{$\begin{array}{l}\text { Quick Response code } \\
\text { Dol: } 10.16965 / \text { ijims.2018.134 }\end{array}$} & \multicolumn{2}{|c|}{$\begin{array}{l}\text { International Journal of Integrative Medical Sciences } \\
\text { ISSN (P): } 2394 \text { - 6318. ISSN (E): } 2394-4137 \\
\text { www.imedsciences.com }\end{array}$} \\
\hline & $\begin{array}{l}\text { Received: 14-09-2018 } \\
\text { Reviewed: 14-09-2018 }\end{array}$ & $\begin{array}{l}\text { Accepted: 02-10-2018 } \\
\text { Published: 10-10-2018 }\end{array}$ \\
\hline Source of Funding: Self & \multicolumn{2}{|c|}{ Conflicts of interest: None } \\
\hline
\end{tabular}

\section{BACKGROUND}

The number of caesarean sections has increased over the last two decades, especially in the developed countries. Hence, it has increasingly become a greater challenge to provide care for the parturient, but this has given obstetric anesthetists a greater opportunity to contribute to obstetric services. While caesarean deliveries were historically performed using general anaesthesia, there is a recent significant move towards regional spinal anesthesia [1].
The incidence of hypotension during cesarean section under spinal anesthesia has been reported to be $80-90 \%$ or greater depending on the definition used [2]. For the mother, hypotension is especially associated with nausea and vomiting and in more severe cases there may be risk of decreased consciousness, pulmonary aspiration, respiratory depression, and cardiac arrest. Hypotension can have detrimental effects on neonate, which include decrease in uteroplacental flow, impaired fetal oxygenation 
with asphyxial stress, and fetal acidosis [3].

Because hypotension may be associated with both maternal and neonatal morbidity, many different methods have been investigated alone and in combination for both its prevention and treatment. Left uterine displacement is known to decrease the effects of aortocaval compression [4]. Leg elevation alone has not been shown to reduce the incidence of hypotension. Prehydration or preloading is commonly administered but it has controversial results [5].

Because of the poor efficacy of nonpharmacological techniques to effectively manage hypotension, a vasopressor is usually required during spinal anesthesia for cesarean section. In choosing an appropriate vasopressor in obstetrics, a number of factors like efficacy for maintaining blood pressure, noncardiovascular maternal effects, ease of use, direct and indirect fetal effects, cost, and availability need to be considered.

Phenylephrine is a potent direct-acting alpha agonist. In pregnancy, because of a generalized reduction in pressor response to endogenous and exogenous vasoconstrictors [6], relatively large doses of phenylephrine may be required. However, fetal acidosis has not been demonstrated when phenylephrine is used liberally to maintain maternal blood pressure and prevent symptoms [7].

Ephedrine is an alkaloid with potent alpha and beta agonist and acts both by direct as well as indirect mechanism. It has been the vasopressor of choice the vasopressor of choice because it has been shown to have a more protective effect on uterine blood flow and perfusion pressure than á-adrenergic agonists in gravid ewes and humans [7]. However, it has been found out that ephedrine administration is associated with significant increases in fetal heart rate and beat-to-beat variability. These changes are dose related and are not associated with fetal asphyxia as judged by the measurement of fetal scalp blood pH or Apgar scores.

The present study was designed to assess the effectiveness of ephedrine and phenylephrine in preventing and treating hypotension in spinal anesthesia for cesarean section and their effect on fetal outcome

\section{SUBJECTS AND METHODS}

This prospective study was conducted at Department of anesthesia in association with department of obstetrics and gynecology at S.M.S Medical college, Jaipur,Rajasthan,India after obtaining ethical committee permission.

Inclusion criteria: Study includes 120 ASA grade I patients undergoing elective cesarean section under spinal anesthesia with a normal singleton pregnancy beyond 36 weeks gestation were recruited.

Exclusion criteria: Patients with pregnancyinduced hypertension, history of diabetes, cardiovascular and cerebrovascular disease, fetal abnormalities, and contraindication to spinal anesthesia were excluded from the study. Patients were randomly allocated into two groups of 60 each.

Group 1 received prophylactic bolus of ephedrine $10 \mathrm{mg} \mathrm{IV}$ at the time of intrathecal block, plus rescue boluses of $5 \mathrm{mg}$ ephedrine, whenever maternal systolic blood pressure was less than $90 \mathrm{mmHg}$.

Group 2 received prophylactic bolus of 109ug IV of phenylephrine at the time of intrathecal block, plus rescue boluses of $50 \mu \mathrm{g}$ phenylephrine, whenever maternal systolic blood pressure was less than $90 \mathrm{mmHg}$ In order to maintain blinding, the vasopressor solutions were prepared in identical syringes by an anesthetist or investigator who was not involved in subsequent patient care. Each subject received oral ranitidine $150 \mathrm{mg}$ on the evening before and 2 hours preoperatively as premedication with a sip of water.

On arrival in the operation theatre heart rate (ECG), blood pressure (NIBP), respiratory rate, and arterial $\mathrm{O} 2$ saturation ( $\mathrm{SaO} 2$ ) were monitored. An infusion of normal saline was started in all patients and preloaded with $10 \mathrm{ml} /$ $\mathrm{kg}$ of normal saline. Patients were placed in lateral or sitting position according to their convenience. Lumbar puncture was performed with 25 gauge Quincke's needle in L3-L4 intervertebral space. Once free flow of cerebrospinal fluid was obtained, $2.5 \mathrm{ml}$ of $0.5 \%$ bupivacaine was administered over 10-15 seconds. 
Time of injection of drug was noted and patient was placed in supine position immediately with a left lateral tilt of 15-20 degrees. Inspired air was supplemented with oxygen at $5 \mathrm{I} / \mathrm{min}$ until clamping of umbilical cord. Immediately after induction of spinal anesthesia, systolic blood pressure, diastolic blood pressure, and heart rate were recorded. One minute after intrathecal injection, patients were given either phenylephrine $100 \mu \mathrm{g}$ IV bolus or ephedrine $10 \mathrm{mg}$ IV bolus. Hemodynamic variables like blood pressure and heart rate was recorded every 2 minutes up to delivery of baby and then after every 5 minutes. Whenever systolic blood pressure decreased to less than $90 \mathrm{mmHg}$, vasopressor was administered, either $5 \mathrm{mg}$ of ephedrine or $50 \mu \mathrm{g}$ of phenylephrine. On each occasion when maternal heart rate decreased to below 60 beats per minute (bpm), atropine $0.3 \mathrm{mg}$ IV was administered. Neonatal outcome was assessed using Apgar score at 1 and 5 minutes. At delivery umbilical cord was clamped and 1 $\mathrm{ml}$ of blood sample collected in heparinized syringe for acid base analysis.

Statistical analysis: All obtained data were analyzed statistically to calculate Mean, SD, and P value by using graph pad prizam software. $P$ value less than 0.01 is considered as a difference of significance.

\begin{tabular}{|c|c|c|c|c|}
\hline $\begin{array}{c}\text { Table 1: Age and weight wise distribution of the } \\
\text { participants. }\end{array}$ & Parameter & $\begin{array}{c}\text { Group } 1(n=60) \\
\text { (Mean } \pm \text { SD) }\end{array}$ & $\begin{array}{c}\text { Group } 2 \\
(n=60) \\
\text { (Mean } \pm \text { SD) }\end{array}$ & P-value \\
\hline \multirow{2}{*}{$>0.01$ (NS): Not significant, $<0.01(\mathrm{~S})$ :Significant } & Age (yr) & $31.52 \pm 1.12$ & $30.85 \pm 0.96$ & $>0.01(\mathrm{NS})$ \\
\hline & Wt(kg) & $64.53 \pm 2.56$ & $68.55 \pm 3.56$ & $>0.01(\mathrm{NS})$ \\
\hline
\end{tabular}

Table 2: Comparison of heart rate, systolic and diastolic blood pressure between groups 1 and 2 before delivery.

\begin{tabular}{|c|c|c|c|c|c|c|c|c|c|}
\hline \multirow{2}{*}{$\begin{array}{c}\text { Parameter till } \\
\text { delivery }\end{array}$} & \multicolumn{3}{|c|}{ Heart rate (bpm) } & \multicolumn{3}{c|}{ BP systolic (mmHg) } & \multicolumn{3}{c|}{ BP Diastolic (mmHg) } \\
\cline { 2 - 10 } & $\begin{array}{c}\text { Group 1 } \\
\text { (Mean } \pm \text { SD) }\end{array}$ & $\begin{array}{c}\text { Group 2 } \\
\text { (Mean } \pm \text { SD) }\end{array}$ & P value & $\begin{array}{c}\text { Group 1 } \\
\text { (Mean } \pm \text { SD) }\end{array}$ & $\begin{array}{c}\text { Group 2 } \\
\text { (Mean } \pm \text { SD) }\end{array}$ & P value & $\begin{array}{c}\text { Group 1 } \\
\text { (Mean } \pm \text { SD) }\end{array}$ & $\begin{array}{c}\text { Group 2 } \\
\text { (Mean } \pm \text { SD) }\end{array}$ & P value \\
\hline $\begin{array}{c}\text { Immediately } \\
\text { after SA }\end{array}$ & $94.56 \pm 15.3$ & $85.26 \pm 13$ & $>0.01$ & $108.50 \pm 15.23$ & $107.50 \pm 20.50$ & $>0.01$ & $70.55 \pm 10.56$ & $69.55 \pm 10.50$ & $>0.01$ \\
\hline $2 \mathrm{~min}$ & $98.23 \pm 11.53$ & $84.56 \pm 15.23$ & $<0.01$ & $118.10 \pm 14.55$ & $115.56 \pm 18.44$ & $>0.01$ & $76.52 \pm 11.75$ & $72.52 \pm 12.85$ & $>0.01$ \\
\hline $4 \mathrm{~min}$ & $99.25 \pm 10.5$ & $82.56 \pm 14.50$ & $<0.01$ & $110.52 \pm 24.50$ & $112.56 \pm 20.50$ & $>0.01$ & $73.56 \pm 20.32$ & $74.52 \pm 18.56$ & $>0.01$ \\
\hline $6 \mathrm{~min}$ & $92.53 \pm 9.5$ & $82.88 \pm 15.56$ & $<0.01$ & $107.50 \pm 15.50$ & $110.50 \pm 14.60$ & $>0.01$ & $74.60 \pm 18.52$ & $73.56 \pm 15.23$ & $>0.01$ \\
\hline $8 \mathrm{~min}$ & $93.56 \pm 10.5$ & $85.56 \pm 13.56$ & $<0.01$ & $109.56 \pm 10.52$ & $112.56 \pm 12.50$ & $>0.01$ & $73.56 \pm 20.32$ & $74.52 \pm 18.56$ & $>0.01$ \\
\hline $10 \mathrm{~min}$ & $91.23 \pm 11.5$ & $84.23 \pm 12.56$ & $<0.01$ & $109.84 \pm 10.49$ & $105.76 \pm 14.58$ & $>0.01$ & $76.56 \pm 15.23$ & $75.56 \pm 14.23$ & $>0.01$ \\
\hline $12 \mathrm{~min}$ & $90.53 \pm 14.56$ & $87.56 \pm 17.53$ & $<0.01$ & $109.56 \pm 12.46$ & $108.56 \pm 12.52$ & $>0.01$ & $76.15 \pm 25.23$ & $75.23 \pm 15.23$ & $>0.01$ \\
\hline $14 \mathrm{~min}$ & $97 \pm 4.56$ & $95.56 \pm 4.56$ & $>0.01$ & $116.50 \pm 5.68$ & $116.20 \pm 5.02$ & $>0.01$ & $72.65 \pm 10.23$ & $73.0 \pm 14.25$ & $>0.01$ \\
\hline
\end{tabular}

$>0.01$ (NS): Not significant, $<0.01(\mathrm{~S})$ :Significant

\section{RESULTS}

Study includes total 120 participants and they were randomly divided in to 2 group and each group consist of 60 participants.

Group 1: Received prophylactic bolus of ephedrine $10 \mathrm{mg}$ IV at the time of intrathecal block, plus rescue boluses of $5 \mathrm{mg}$ ephedrine Group2: Received prophylactic bolus of $100 \mu \mathrm{g}$ IV of phenylephrine at the time of intrathecal block, plus rescue boluses of $50 \mathrm{gg}$ phenylephrine

The difference observed in baseline heart rate, systolic, diastolic, and mean blood pressures between two groups was statistically insignificant [Table 2]. There was higher incidence of bradycardia in patients receiving phenylephrine than those receiving ephedrine. The difference in mean heart rate till delivery compared between two groups immediately after spinal anesthesia, at 2, 4, 6, 8, 10, and 12 minutes was significant while it was insignificant at 0 and 14 minutes ( $P$ value $<0.05$ : significant). The difference in mean heart rate compared between two groups at delivery, 5, 10, minutes and at the end of the surgery was insignificant except at delivery and 15 minutes after delivery ( $P$ value < 0.05: significant) [Tables 2 and 3]. 
Table 3: Comparison of heart rate, systolic and diastolic blood pressure between groups 1 and 2 after delivery.

\begin{tabular}{|c|c|c|c|c|c|c|c|c|c|}
\hline \multirow{2}{*}{$\begin{array}{c}\text { Parameter after } \\
\text { delivery }\end{array}$} & \multicolumn{3}{|c|}{ Heart rate (bpm) } & \multicolumn{3}{c|}{ BP systolic (mmHg) } & \multicolumn{3}{c|}{ BP Diastolic (mmHg) } \\
\cline { 2 - 10 } & $\begin{array}{c}\text { Group 1 } \\
\text { (Mean } \pm \text { SD) }\end{array}$ & $\begin{array}{c}\text { Group 2 } \\
\text { (Mean } \pm \text { SD) }\end{array}$ & P value & $\begin{array}{c}\text { Group 1 } \\
\text { (Mean } \pm \text { SD) }\end{array}$ & $\begin{array}{c}\text { Group 2 } \\
\text { (Mean } \pm \text { SD) }\end{array}$ & P value & $\begin{array}{c}\text { Group 1 } \\
\text { (Mean } \pm \text { SD) }\end{array}$ & $\begin{array}{c}\text { Group 2 } \\
\text { (Mean } \pm S D)\end{array}$ & P value \\
\hline At delivery & $96.50 \pm 14.50$ & $92.76 \pm 14.0$ & $>0.01$ & $118.50 \pm 14.23$ & $124.50 \pm 20.50$ & $>0.01$ & $76.55 \pm 10.56$ & $78.55 \pm 10.50$ & $>0.01$ \\
\hline 5 min & $94.23 \pm 12.53$ & $88.56 \pm 15.23$ & $>0.01$ & $112.10 \pm 11.55$ & $118.56 \pm 18.44$ & $>0.01$ & $74.52 \pm 10.75$ & $72.52 \pm 12.85$ & $>0.01$ \\
\hline 10 min & $88.35 \pm 10.5$ & $85.56 \pm 12.50$ & $>0.01$ & $116.52 \pm 14.50$ & $112.56 \pm 20.50$ & $>0.01$ & $76.56 \pm 18.32$ & $74.52 \pm 18.56$ & $>0.01$ \\
\hline 15 min & $92.53 \pm 9.5$ & $82.88 \pm 15.56$ & $<0.01$ & $114.50 \pm 13.50$ & $109.50 \pm 14.60$ & $>0.01$ & $75.60 \pm 18.52$ & $73.56 \pm 15.23$ & $>0.01$ \\
\hline 20 min & $93.56 \pm 10.5$ & $88.56 \pm 13.56$ & $>0.01$ & $118.56 \pm 8.52$ & $102.56 \pm 12.50$ & $>0.01$ & $71.56 \pm 20.32$ & $66.52 \pm 18.56$ & $>0.01$ \\
\hline End of surgery & $91.12 \pm 11.5$ & $84.88 \pm 12.98$ & $>0.01$ & $116.84 \pm 8.49$ & $118.76 \pm 12.58$ & $>0.01$ & $75.26 \pm 15.23$ & $72.36 \pm 14.23$ & $>0.01$ \\
\hline
\end{tabular}

$>0.01$ (NS): Not significant, $<0.01(\mathrm{~S})$ :Significant

The difference in systolic, diastolic, and mean blood pressure between two groups till delivery and after delivery at all times was statistically insignificant. Overall, 42/60 (70\%) patients in the phenylephrine group and 38/60 (64\%) patients in ephedrine group had one or more episode of hypotension and required one or more bolus of vasopressor.[Table 4 and 5]

The difference in birth weight of neonates between two groups was statistically nonsignificant [Table 6]. No neonate had Apgar score $<7$ at 1 or 5 minute.

Table 4: Comparison of mean blood pressure $(\mathrm{mmHg})$ till delivery between groups 1 and 2 .

\begin{tabular}{|c|c|c|c|}
\hline $\begin{array}{l}\text { Mean BP } \\
(\mathrm{mmHg})\end{array}$ & $\begin{array}{c}\text { Group } 1 \\
\text { (Mean } \pm S D\end{array}$ & $\begin{array}{c}\text { Group } 2 \text { (Mean } \pm \\
\text { SD) }\end{array}$ & $P$ value \\
\hline $\begin{array}{c}\text { Immediately } \\
\text { after SA }\end{array}$ & $84.56 \pm 10.56$ & $82.50 \pm 15.53$ & $>0.01$ \\
\hline $2 \min$ & $92.80 \pm 10.5$ & $84.24 \pm 12.52$ & $>0.01$ \\
\hline $4 \mathrm{~min}$ & $88.10 \pm 12.56$ & $86.22 \pm 10.52$ & $>0.01$ \\
\hline $6 \mathrm{~min}$ & $90.10 \pm 11.50$ & $88.12 \pm 8.50$ & $>0.01$ \\
\hline $8 \mathrm{~min}$ & $86.20 \pm 12.56$ & $84.20 \pm 14.50$ & $>0.01$ \\
\hline $10 \mathrm{~min}$ & $92.5 \pm 9.15$ & $85.13 \pm 12.23$ & $>0.01$ \\
\hline $12 \mathrm{~min}$ & $88.56 \pm 12.23$ & $90.52 \pm 9.13$ & $>0.01$ \\
\hline $14 \mathrm{~min}$ & $86.12 \pm 10.23$ & $86.56 \pm 13.23$ & $>0.01$ \\
\hline
\end{tabular}

$>0.01$ (NS): Not significant, <0.01(S) :Significant

Table 5: Comparison of mean blood pressure $(\mathrm{mmHg})$ after delivery between groups 1 and 2 .

\begin{tabular}{|c|c|c|c|}
\hline Mean BP $(\mathbf{m m H g})$ & $\begin{array}{c}\text { Group 1 } \\
(\text { Mean } \pm \text { SD }\end{array}$ & $\begin{array}{c}\text { Group 2 (Mean } \pm \\
\text { SD) }\end{array}$ & P value \\
\hline At delivery & $90.46 \pm 10.56$ & $90.50 \pm 15.53$ & $>0.01$ \\
\hline $\mathbf{5}$ min & $87.80 \pm 10.5$ & $846.24 \pm 12.52$ & $>0.01$ \\
\hline $\mathbf{1 0} \mathbf{~ m i n}$ & $89.10 \pm 12.56$ & $86.22 \pm 10.52$ & $>0.01$ \\
\hline $\mathbf{1 5} \mathbf{~ m i n}$ & $88.10 \pm 11.50$ & $90.12 \pm 8.50$ & $>0.01$ \\
\hline $\mathbf{2 0}$ min & $86.10 \pm 12.56$ & $82.20 \pm 14.50$ & $>0.01$ \\
\hline End of surgery & $89.5 \pm 8.15$ & $85.13 \pm 11.23$ & $>0.01$ \\
\hline
\end{tabular}

$>0.01$ (NS): Not significant, $<0.01(\mathrm{~S})$ :Significant
Table 6: Comparison of birth weight groups 1 and 2 .

\begin{tabular}{|c|c|}
\hline Parameter & Birth wt (kg) \\
\hline Group 1 & $2.930 \pm 0.50$ \\
\hline Group 2 & $3.065 \pm 0.42$ \\
\hline P value & $>0.01$ \\
\hline
\end{tabular}

$>0.01$ (NS): Not significant, $<0.01(\mathrm{~S})$ :Significant

\section{DISCUSSION}

Despite more than three decades of research, hypotension during spinal anesthesia for cesarean delivery remains a common clinical problem that is associated with morbidity for both mother (nausea and vomiting) and fetus (fetal acidosis). An effective method for preventing hypotension has been referred to as the "Holy Grail" of obstetric anesthesia [8] and has yet to be described. Techniques currently in use for preventing hypotension include intravenous fluid prehydration [9], sympathomimetic drugs, [10] and physical methods such as leg bindings and compression stockings [11]. However, a Cochrane review concluded that none of these techniques alone was effective in eliminating hypotension and suggested that future research be directed toward investigation of combinations of interventions.

Overall incidence of hypotension during spinal anesthesia in cesarean section is $80 \%$. Hypotension can have detrimental effects on both mother and neonate. These effects include decrease in uteroplacental blood flow, impaired fetal oxygenation with asphyxia stress, fetal acidosis, and maternal symptoms of low cardiac output such as nausea, vomiting, dizziness, and decreased consciousness [12].

In this study, all patients in the two groups were comparable with respect to age and ASA status. 
The difference observed in baseline parameters, that is, pulse, systolic, diastolic, and mean arterial pressures between two groups was statistically insignificant, respectively. There was statistically nonsignificant difference between surgical times (induction to delivery time and from delivery till end of surgery) in groups 1 and 2.

A number of other recent studies have also investigated the use of intravenous cohydration. Dyer et al. [13] randomly assigned patients to receive $20 \mathrm{ml} / \mathrm{kg}$ modified Ringer's lactate solution either before or immediately after induction of spinal anesthesia for elective cesarean delivery. They found that patients who received fluid after induction had a smaller requirement for ephedrine. Similarly, Mercier et al. ${ }^{[14]}$ randomly assigned parturients to receive $1 \mathrm{I}$ crystalloid before or after induction. They found no difference in vasopressor requirement between groups. However, vasopressor requirement was inversely correlated with the speed of crystalloid administration in patients who received fluid after induction; therefore, they concluded that fluid should be given as quickly as possible

In this study, there was higher incidence of bradycardia in patients receiving phenylephrine than those receiving ephedrine This is expected to be due to increase in blood pressure with an á-agonist may lead to reactive bradycardia (baroreceptor reflex). However, this was responsive to atropine without adverse consequences. Atropine was required in 17 of 50 patients in group 2 compared with 5 of 50 patients in group

The results of this study were in accordance with the study of Lee et al. [15] in which they reported higher incidence of bradycardia in patients receiving phenylephrine as compared with patients receiving ephedrine for prevention of hypotension during spinal anesthesia for cesarean section.

The results of this study are in accordance with the study of Adigun et al. [16] They observed that both vasopressors effectively restored both the systolic and diastolic blood pressure. They also concluded that phenylephrine is safe and can be used as effectively as ephedrine.

This study is not consistent with the work of
Magalhães et al. [17] study on ephedrine versus phenylephrine for prevention of hypotension during spinal block for cesarean section and effects on fetus. They concluded that ephedrine was more effective than phenylephrine in the prevention of hypotension. This may have been because less dose of phenylephrine was used in their study as compared with this study.

There was no difference in Apgar score between the two groups. In this study, no neonate had an Apgar score $<7$ at 1 or at 5 minutes. The difference in birth weight of neonates between two groups was statistically non-significant.

\section{CONCLUSION}

From my study it was concluded that both phenylephrine and ephedrine are equally efficient vasopressor agent in management of hypotension during spinal anesthesia for elective cesarean delivery. Neonatal outcome remains equally good in both the groups.

\section{REFERENCES}

[1]. Black C, Kaye JA, Jick H. Cesarean delivery in the United Kingdom: time trends in the general practice research database. Obstet Gynecol. 2005;106:1515.

[2]. Prakash S, Pramanik V, Chellani H, Salhan S, Gogia AR. Maternal and neonatal effects of bolus administration of ephedrine and phenylephrine during spinal anaesthesia for caesarean delivery: A randomized study. Int J Obstet Anesth 2010;19:24-30.

[3]. Balki M, Carvalho JC. Intraoperative nausea and vomiting during cesarean section under regional anesthesia. Int J Obstet Anesth 2005;14:230-41.

[4]. Lee A, Warwick D, Kee N, Gin T. Trails of ephedrine versus phenylephrine for the management of hypotension during spinal anaesthesia for caesarean section. Anaesth Analg 2002;94:920-6.

[5]. Rout CC, Rocke DA, Gouws E. Leg elevation and wrapping in the prevention of hypotension following spinal anaesthesia for elective caesarean section. Anaesthesia 1993;48:304-8.

[6]. Ralston DH, Shnider SM, deLorimier AA. Effects of equipotentephedrine, metaraminol,mephentermine, and methoxamine on uterineblood $\mathrm{fl}$ ow in the pregnant ewe. Anesthesiology 1974;40:354-70.

[7]. Ngan Kee WD, Khaw KS, Ng FF. Comparison of phenylephrine infusionregimens for maintaining maternal blood pressure during spinalanaesthesia for caesarean section. Br J Anaesth 2004;92:469-74.

[8]. Macarthur A: Solving the problem of spinal-induced hypotension in obstetric anesthesia/Traiter hypotension induite par la rachnianesthésie en obstétrique. CanJ Anesth 2002; 49:536-9. 
[9]. Wollman SB, Marx GF: Acute hydration for prevention of hypotension of spinal anesthesia in parturients. Anesthesiology 1968; 29:374-80.

[10]. Kang YG, Abouleish E, Caritis S: Prophylactic intravenous ephedrine infusion during spinal anesthesia for cesarean section. Anesth Analg 1982; 61:839-42.

[11]. Rout CC, Rocke DA, Gouws E: Leg elevation and wrapping in the prevention of hypotension following spinal anaesthesia for elective caesarean section. Anaesthesia 1993; 48:304-8.

[12]. Balki M, Carvalho JC. Intraoperative nausea and vomiting during cesarean section under regional anesthesia. Int J Obstet Anesth 2005;14:230-41.

[13]. Dyer RA, Farina Z, Joubert IA, Du Toit P, Meyer M, Torr G, Wells K, James MFM: Crystalloid preload versus rapid crystalloid administration after induction of spinal anaesthesia (coload) for elective caesarean section. Anaesth Intensive Care 2004; 32:351-7.

[14]. Mercier FJ, Roger-Christoph S, des Mesnard-Smaja V, Westerman M, Foiret C, Fischler M, Benhamou D: Crystalloid pre-loading vs. post-loading for the prevention of hypotension with spinal anesthesia for cesarean delivery (abstract). Anesthesiology 2004; 100:A18.
[15]. Lee A, Warwick D, Kee N, Gin T. Trails of ephedrine versus phenylephrine for the management of hypotension during spinal anaesthesia for caesarean section. Anaesth Analg 2002;94:920-6.

[16]. Adigun TA, Amanor-Boadu SD, Soyannwo SD. Comparison of intravenous ephedrine with phenylephrine for the maintenance of arterial blood pressure during elective caesarean section under spinal anaesthesia. Afr J Med Med Sci 2010;39:13-20.

[17]. Magalhaes E, Goveia CS, Ladeira LC, Nascimento BG. Ephedrine versus phenylephrine: Prevention of hypotension during spinal block for cesarean section and eff ects on the fetus. Rev Bras Anestesiol 2009;59:11-20.

$$
\begin{aligned}
& \text { How to cite this article: Chand kiran Yadav. STUDY OF COMPARISON } \\
& \text { BETWEEN EPHEDRINE AND PHENYLEPHRINE FOR PREVENTION OF } \\
& \text { HYPOTENSION DURING SPINAL ANESTHESIA FOR CESAREAN SECTION. } \\
& \text { Int J Intg Med Sci 2018;5(8):729-734. DOI: } 10.16965 / \text { ijims.2018.134 }
\end{aligned}
$$

